\title{
The Application of Chinese Traditional Auspicious Patterns in Yves Saint Laurent Fashion Design
}

\author{
Zhanrong Shi ${ }^{1, *}$ \\ ${ }^{1}$ Fuzhou University of International Studies and Trade, Fuzhou, Fujian, China \\ *Corresponding author. Email:2753006833@qq.com
}

\begin{abstract}
Through literature review, this research analyzes the six creative methods of traditional Chinese auspicious patterns, such as symbol design, the application of phonetic loan characters, the application of personification, signify-functional design, the application of homophony, and the application of embedded characters. With the discussion on the application of oriental elements to international fashion, the connotation of Chinese culture is deconstructed, and the concept of environmental protection is proposed at the same time, showing the traditional Chinese value and the sustainable fashion in the international trend.
\end{abstract}

\section{Keywords: dress, sustainable fashion, traditional Chinese culture}

\section{INTRODUCTION}

In "Culture is good business", Feng Jiuling said: "Culture is the best value-creation capital. Regardless of landscape, garden, architecture, religion, folk custom, history, cooking, wine, tea or other artistic and cultural assets, they all contain the important wisdom and skills handed down by a nation for thousands of years, which will bring rich inspiration and materials for large and small-sized industries and cultural tourism." Dress is of profound significance all over the world. With the rapid development of information and transportation, people have more ideas on the selection of formal dress. In addition to following the international fashion trend, they also care about the display of their own cultures.

\section{A. Research background and motivation}

With the development of human society, the transmission of transportation and culture is getting faster and faster. In the early Republic of China, dress has gradually westernized, and fishtail skirt, tights, and bubble skirt have gradually become the mainstream of dress market. So far, people have a variety of choices of ceremony forms and clothing, which are no longer limited to tradition. They have more ideas on personal consciousness and style. After nearly a hundred years of popularity of Western-style wedding dress, many people begin to dress Chinese-style dresses in important occasions. In addition to international popular styles, they pay attention to the display of their own culture.

In the fashion industry, the amount of textile waste in the world has exceeded the environmental load. The textile waste can be decomposed and recycled.
However, due to its low economic value, most garment factories will directly send the leftover fabric to the landfill, wasting the resources consumed. Nowadays, "sustainability" has become a challenge for all walks of life, and it is also the responsibility of modern human beings. In Feng Jiuling's "culture is good business", "Modern consumers are more aware of their own needs. They want to obtain more values from consumption beyond product functions, have higher environmental awareness, focus on their political values, and pay attention to the connotation and pursuit of depth." Nowadays, many fashion brands promote environmentally-friendly products. In addition to fashion, if brands can present culture and environmental protection in customized clothing, they can strengthen the value inheritance of sustainable good image and culture.

\section{B. Research purposes}

It is hoped that through the discussion of Chinese cultural customs and totems, as well as the meaning conveyed, environmental protection will be integrated into the design, and the concept of dress which can show Chinese culture and environmental awareness in the international trend is put forward.

\section{LITERATURE REVIEW}

\section{A. Chinese blessing}

Chinese people are used to symbolizing specific thoughts according to the shape or habit of things. Therefore, there are many ways to express good luck and convey blessings. One of them is the pattern with 
auspiciousness. The traditional robe of patches can show the blessings of others from thrift.

\section{B. Auspicious patterns}

Auspicious totems have been used in bronze mirrors since the Warring States period in China. The patterns with implied meanings can be seen in colorful brocades, portraits, sculptures, buildings and utensils. Especially after the Yuan Dynasty, patterns with auspiciousness were popular among the people.
Therefore, the implied meanings of patterns were greatly associated, showing the situation that "the pictures must be intentional, and the meanings must be auspicious". The six methods are shown in Table I", such as symbol-shape design, the application of phonetic loan characters, the application of personification, signify-functional design, homophonic design, and the application of embedded characters. (Gao Chunming, 2010)

TABLE I. AUSPICIOUS PATTERNS

\begin{tabular}{|c|c|c|}
\hline Method & Explanation & Example \\
\hline $\begin{array}{l}\text { Symbol-shape } \\
\text { design }\end{array}$ & $\begin{array}{l}\text { To express a particular } \\
\text { thought according to its } \\
\text { form or habit }\end{array}$ & $\begin{array}{l}\text { Using pomegranate seeds to symbolize many children and grandchildren } \\
\text { Source: http://s11.sinaimg.cn/mw690/003orzemzy6s7ymrpj01a\&690 }\end{array}$ \\
\hline $\begin{array}{l}\text { The application } \\
\text { of phonetic } \\
\text { loan characters }\end{array}$ & $\begin{array}{l}\text { To express auspiciousness } \\
\text { with the things people like } \\
\text { to see and hear }\end{array}$ & $\begin{array}{l}\text { Using three durable plants of winter, such as pine, bamboo and plum to show } \\
\text { noble personality } \\
\text { Source: http://img3.redocn.com/20120615/redocn_2012061515312738.jpg }\end{array}$ \\
\hline $\begin{array}{l}\text { The application } \\
\text { of } \\
\text { personification }\end{array}$ & $\begin{array}{l}\text { Using personification to } \\
\text { express auspiciousness }\end{array}$ & $\begin{array}{l}\text { hource: } \\
\text { http://www.rakuten.ne.jp/gold/fusimiya/images/shouhin/5gatsu/nabata/tin10- } \\
\text { 250/img12052.jpg }\end{array}$ \\
\hline $\begin{array}{l}\text { Signify- } \\
\text { functional } \\
\text { design }\end{array}$ & $\begin{array}{l}\text { To express implied } \\
\text { meaning according to } \\
\text { traditional custom }\end{array}$ & $\begin{array}{l}\text { Gold ingot are used to represent the wealth } \\
\text { Source: http://gd3.alicdn.com/bao/uploaded/i3/ } \\
\text { T1_6a7flhaxxxxxxxx_!!0-item_pic.jpg_400x400.jpg }\end{array}$ \\
\hline $\begin{array}{l}\text { The application } \\
\text { of homophony }\end{array}$ & $\begin{array}{l}\text { Using the pronunciation or } \\
\text { homophony of things to } \\
\text { convert them into } \\
\text { auspicious patterns }\end{array}$ & $\begin{array}{l}\text { "蝠" (bat) is used to express "blessing" } \\
\text { Source: http://img1.tplm123.com/2008/07/28/1573/-20240270785574.jpg }\end{array}$ \\
\hline $\begin{array}{l}\text { The application } \\
\text { of embedded } \\
\text { words }\end{array}$ & $\begin{array}{l}\text { Inserting text directly into } \\
\text { the drawing }\end{array}$ & The characters and patterns of "暿" (happiness) are used together \\
\hline
\end{tabular}




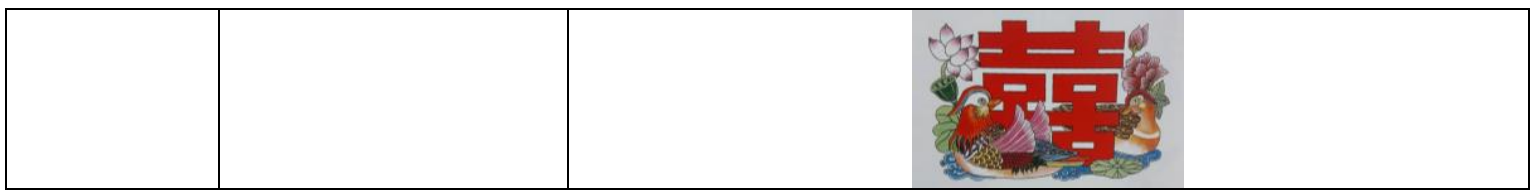

- symbol-shape design: it is to express specific ideas according to the form or habit of things, such as using pomegranate with many seeds to symbolize many children and grandchildren; using mandarin ducks living together to symbolize love and specificity.

- the application of phonetic loan characters: it is to express auspicious meanings with things people like to see and hear, such as using pine, bamboo and plum to show noble personality.

- the application of personification: it is to use personification to express auspicious meanings. For example, fierce tiger can be used to represent a hero.

- signify-functional design: it is to express the implied meaning according to the traditional custom. For example, the Jade Hare represents the moon, and the gold ingot represents wealth.
- the application of homophony: it is to convert the pronunciation or homophony of things into auspicious patterns. For example, "蝠" (bat) is used to express "blessing" and "鹿" (deer) is used to express the wealth.

- the application of embedded words: it is to embed text directly into a drawing.

The above auspicious patterns are used alone sometimes, and are also reorganized sometimes to express richer meanings (as shown in "Table II"). Chinese-style dress is embroidered with auspicious patterns, such as dragon, Phoenix, Peony. In the Qing Dynasty, embroidery was almost embroidered in the whole dress, so as to express the completeness and blessing.

TABLE II. THE RECOMBINATION OF AUSPICIOUS PATTERNS

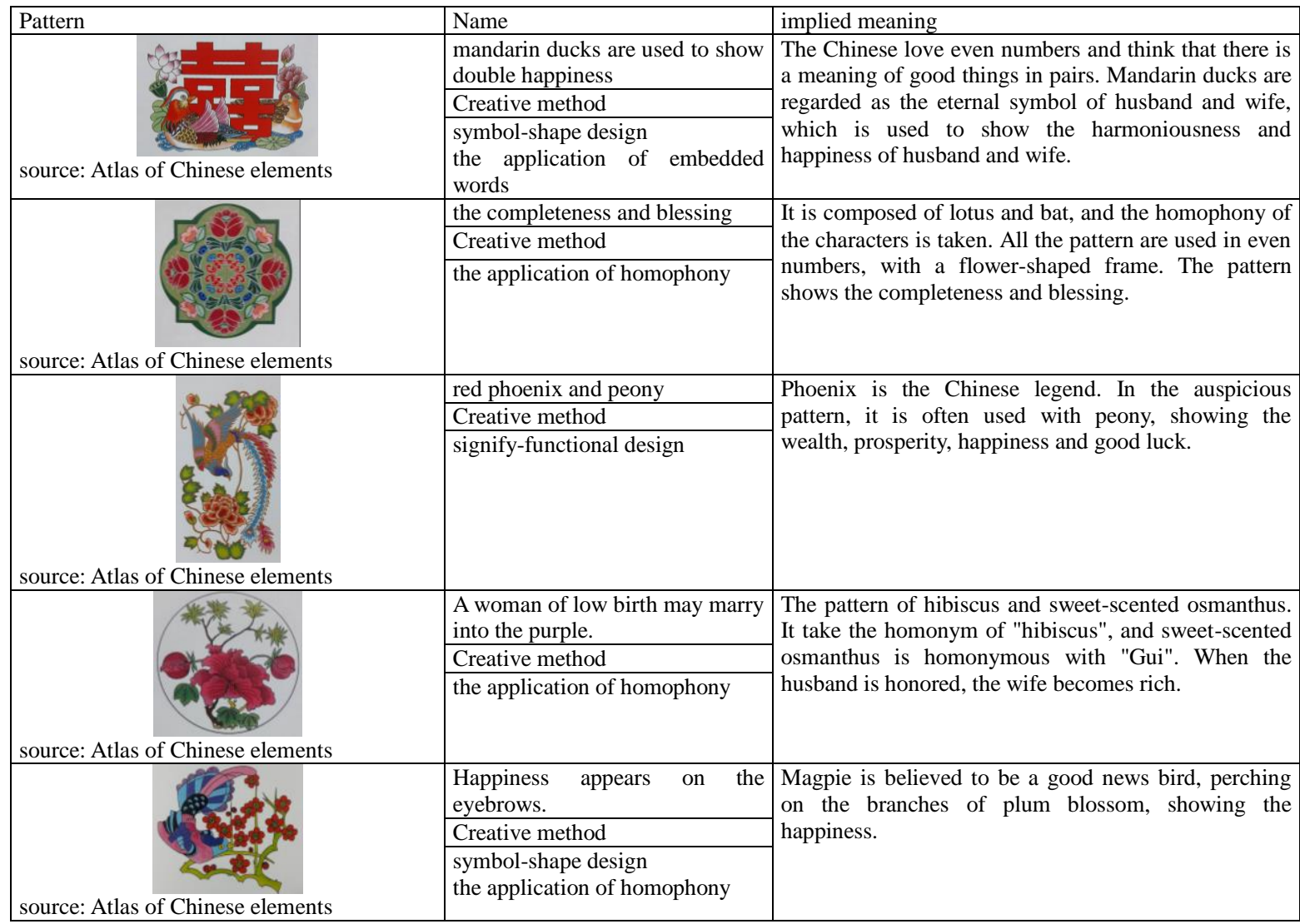




\begin{tabular}{|c|l|l|}
\hline & Pomegranate & $\begin{array}{l}\text { Pomegranate has many seeds, and is often used as a } \\
\text { symbol of many children to bless new people. }\end{array}$ \\
\cline { 2 - 3 } $\begin{array}{c}\text { Creative method } \\
\text { source: Atlas of Chinese elements }\end{array}$ & \\
\hline
\end{tabular}

\section{Folk blessing: ragged robe made of patches}

The behavior of collecting, reusing and cherishing robe of patches is linked to a performance of no waste and saving, which means "sustainable" inheritance.

"衲" originally means patchwork, while "百" means many things. "百衲" (patchwork) is a kind of fabric made of scattered materials. There are two main reasons for the rise of ragged robe made of patches. One is that it breaks the conventional beauty and becomes popular in the Ming and Qing Dynasties. The other is the lack of materials in the early agricultural society. In order to save clothing materials, women would sew together fragmentary cloth and use it as a complete cloth.

The ragged robe made of patches and quilts made of patches have the implied meaning of exorcism and blessing in the folk. The materials are rags collected from neighbors and sewed into clothes, hats and quilts. Because the cloth is made from hundreds of families, it can disturb the gods, and it also means that children are easy-going. Therefore, it is used as a gift to show that the child is long-lived and easy to raise. ("Fig. 1")

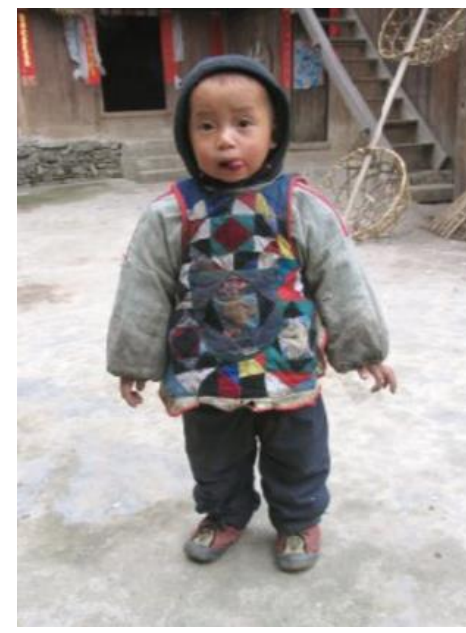

Fig. 1. Children's robe made of patches.

a. source: http://blog.udn.com/stonejung/226342

\section{RESEARCH METHODS}

It is hoped to look for clothing works with east-west style, and analyze the design techniques, which will be a reference for subsequent creation.
In 2004, Yves Saint Laurent clothing series, inspired by China, still contained the line of Chinese cheongsam under the outline of western-style dress. It used digital dot matrix diagram to form oriental auspicious patterns with sequins. Viewing from afar, it had satin-like luster. It combined western techniques with futuristic techniques to bring new interest to oriental elements. For example, the embroidery in Qing Dynasty is used in western-style dress (as shown in "Fig. 2"). The configuration of western lace and pattern is applied to the cheongsam. As shown in "Fig. 2", it can achieve the integration of Chinese and Western clothing patterns and materials, creating new features.

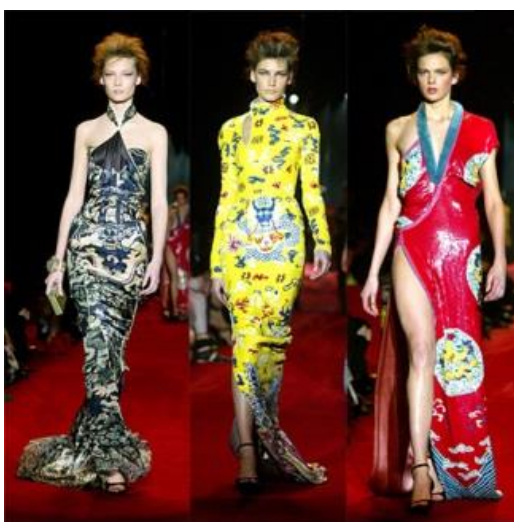

Fig. 2. 2014 Yves Saint Laurent clothing series.

source: http://www.beautimode.com

Inspired by patchwork, 1969 Yves Saint Laurent reconstructed a western dress with irregular pieces of cloth. Although it had the western outline, people could find the eastern elements from the color and printing of the pieces of cloth. At the same time, it used the seam to emphasize the characteristics of patchwork, making imperfection a unique beauty. ("Fig. 3") 


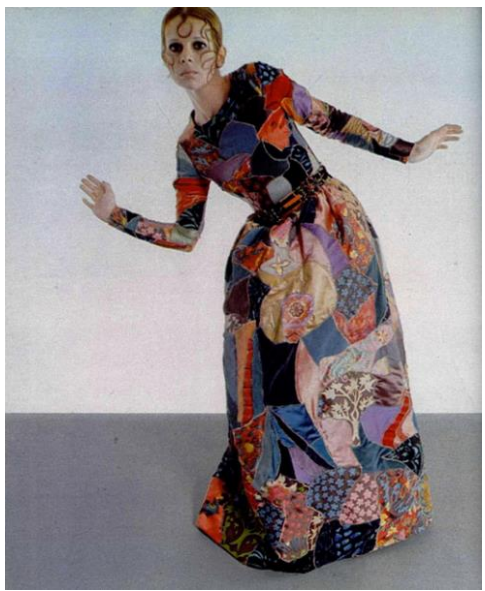

Fig. 3. 1969 Yves Saint Laurent clothing.

source: https://www.flickr.com/photos/teenjetset/8493403422/in/photostream/

All of the above clothing works are inspired by Chinese traditional culture. In addition to the outline, color and material, western thinking is combined. For example, the line of cheongsam is added to the outline of western dress, or the Chinese-style embroidery pattern is presented in the western-style typesetting way, making Chinese traditional culture have a new interpretation.

\section{CONCLUSION}

From the literature review, people can understand the evolution of oriental auspicious totem and the significance of folk blessing. From the designers' interpretation of Chinese and Western clothing, it is found that the Chinese culture has become a major focus of western dress. Therefore, this study puts forward the following concepts.

\section{A. The conversion of auspicious pattern into lace unit}

Lace is widely used in dresses, and the embroidery of auspicious patterns is one of the characteristics of Chinese dress. If the auspicious pattern is converted into the lace unit, and the Chinese pattern is expressed in western style, there will be more freedom in the arrangement of patterns.

\section{B. The application of patchwork technique in pattern expression}

The pattern is a major feature of Chinese dress. The recombination of broken cloth into patterns can not only solve some waste textile, convey the concept of environmental protection, but also create interesting pictures in pictures. ("Fig. 4")

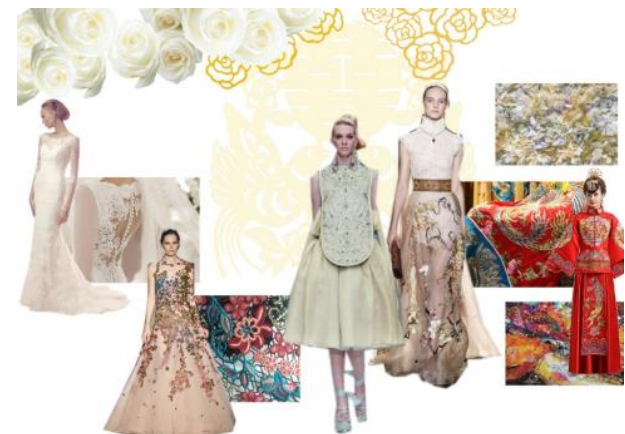

Fig. 4. Design board

Source: drawn by the author.

C. Chinese-style outline and western-style color

Nowadays, in the choice of ceremonial costumes, the beige and white are the preferences of most people, and most Chinese dresses are red with contrast color embroidery. If the outline of Chinese dress is white, beige and other colors, soft color can be used as the embellishment. With the use of yarn, the Chinese dress will perform a western-style romantic expression.

\section{References}

[1] Feng Jiuling. Culture is good business. Nanhai Publishing Company, 2002: 001. (in Chinese)

[2] Hua Mei. Chinese Apparel. China Intercontinental Press, 2007: 61-62. (in Chinese)

[3] Gao Chunming. Dictionary on Chinese Elements. Shanghai Literature and Art Publishing House. 2013: 24-32. (in Chinese)

[4] Cai Yijin. History of Chinese and Western Dresses. 2013:55-82. (in Chinese)

[5] Miao Miao. The evolution of Han wedding dresses, 2017 https://wenku.baidu.com/view/94511a84aeaad1f346933fe9.html

[6] Ye Tianjun. potluck and robe of patches in memory, 2017 https://www.google.com.tw/amp/s/kknews.cc/culture/xp8bnr.a $\mathrm{mp}$ 